\section{Estudo \\ CoDebate}

em Testão

Planejamento
Revista Estudo \& Debate, Lajeado, v. 28, n. 4, 2021. ISSN 1983-036X

DOI: http://dx.doi.org/10.22410/issn.1983-036X.v28i4a2021.2926

\title{
EFEITO DA INFRAESTRUTURA DAS ESCOLAS ESTADUAIS DA REGIÁO METROPOLITANA DO CARIRI NAS NOTAS DE PROFICIÊNCIA DO SPAECE NO PERÍODO DE 2008 A 2015
}

\author{
Manoel Alexandre de Lucena ${ }^{1}$, Eliane Pinheiro de Sousa ${ }^{2}$
}

\begin{abstract}
Resumo: Para avaliar as competências dos alunos nos exames de português e matemática, o estado do Ceará realiza o Sistema de Avaliação Permanente da Educação Básica (SPAECE). Tais avaliaçôes são relevantes ao apontar fatores que influenciam a educação, como é o caso da infraestrutura física das unidades escolares. Neste contexto, o objetivo deste estudo é mensurar o efeito da infraestrutura das escolas estaduais da Regiáo Metropolitana do Cariri (RMC) nas notas de proficiência do SPAECE do primeiro ano do ensino médio no período de 2008 a 2015. Para tal, aplicou-se um modelo de regressão de dados em painel com efeitos fixos. Essa modelagem é caracterizada pela combinação de séries temporais e dados de corte transversal. Os resultados revelaram que a presença de refeitório, laboratório de ciências, internet banda larga, auditório e área verde influenciam de forma positiva as notas de proficiência em português, enquanto o desempenho em matemática é afetado positivamente pela existência de refeitório, diretoria e internet banda larga. Portanto, torna-se necessária implementar políticas adequadas, que promovam equidade entre os insumos escolares, uma vez que a infraestrutura adequada cumpre seu papel primordial na formaçáo do discente, de modo a reduzir as desigualdades econômicas e sociais.
\end{abstract}

Palavras-chave: Infraestrutura escolar. Dados em painel. Desempenho dos alunos no SPAECE.

\section{EFFECT OF THE INFRASTRUCTURE OF STATE SCHOOLS FROM THE METROPOLITAN REGION OF CARIRI ON THE SPAECE'S PROFICIENCY GRADES IN THE PERIOD FROM 2008 TO 2015}

\begin{abstract}
To evaluate the skills of students in Portuguese and Mathematics exams, the State of Ceará carries out the Basic Education Permanent Evaluation System (SPAECE). Such evaluations are relevant in pointing out factors that influence education as is the case with the physical infrastructure of school units. In this context, the purpose of this study is to measure the effect of the infrastructure of state schools from the Metropolitan Region of Cariri on SPAECE's proficiency grades of the first year of high school, in the period from 2008 to 2015. For
\end{abstract}

1 Graduando em Ciências Econômicas na Universidade Regional do Cariri (URCA) e Bolsista de Iniciação Cientifica BPI FUNCAP.

2 Professora da Universidade Regional do Cariri (URCA) e Bolsista de Produtividade em Pesquisa, Estímulo à Interiorização e à Inovação Tecnológica (BPI) da Fundação Cearense de Apoio ao Desenvolvimento Científico e Tecnológico (FUNCAP). 
such purpose, was used a panel data regression model with fixed effects. This modeling is characterized by the combination of time series and cross-sectional data. The results revealed that the presence of a cafeteria, science lab, broadband internet connection, auditorium, school board and green area exerts a positive influence on the proficiency grades in Portuguese, while performance in Mathematics is positively affected by the existence of a cafeteria, board and broadband internet. Thus, it is necessary to implement adequate policies that promote equity among school inputs, since adequate infrastructure fulfills its primary role in student education, to reduce economic and social inequalities.

Keywords: School infrastructure. Panel data. Student performance in SPAECE.

\section{INTRODUÇÁO}

No âmbito das avaliaçóes do sistema educacional brasileiro, o Ceará realiza um levantamento das informaçôes educacionais denominado Sistema de Avaliação Permanente da Educação Básica (SPAECE), que busca avaliar as competências dos alunos de todos os municípios do estado por meio de testes cognitivos - exames de matemática e português -, bem como a aplicação de questionários sobre dados socioeconômicos, hábitos dos alunos e práticas de professores e diretores (SHIRASU; ALBUQUERQUE; ARRAES, 2014).

Tais processos avaliativos são relevantes ao apontar determinantes que influenciam a educaçáo. Nesse sentido, a literatura elenca diversos fatores que exercem influência na qualidade da educação, como background familiar, mercado de trabalho atraente, turmas homogêneas, elementos pedagógicos, infraestrutura, entre outros, conforme Monteiro, Castelar e Sousa (2017). Em sintonia com isso, diversos estudos têm aferido de que forma estes elementos impactam nos resultados avaliativos das escolas.

Nesse sentido, destacam-se pesquisas acadêmicas internacionais e nacionais que contribuíram para explicitar os efeitos da infraestrutura dos ambientes educacionais no desempenho dos discentes: Heyneman e Loxley (1983); Lee, Franco e Albernaz (2004); Felício e Fernandes (2005); Franco et al. (2007); Gomes e Regis (2012); Rocha, Teixeira e Melo (2015); Monteiro, Castelar e Sousa (2017); Silva e Nascimento (2019); e Vasconcelos et al. (2020).

Apesar de o penúltimo estudo ter contemplado parcela majoritária das escolas cearenses na análise dos determinantes da proficiência em língua portuguesa e matemática no SPAECE, o efeito da infraestrutura fora considerado de forma agregada. No presente trabalho, são incluídos os diversos ambientes da infraestrutura física das escolas, como salas de leitura, bibliotecas, laboratórios de informática e ciências, existência de computadores, acesso à internet, entre outros, que influenciam o desempenho dos alunos nas notas de proficiência do SPAECE.

Trompieri Neto et al. (2014) sinalizam que as escolas situadas nas regióes de Baturité, Leste, Metropolitana de Fortaleza e do Cariri, onde se localiza a Regiáo Metropolitana do Cariri (RMC), objeto de estudo deste artigo, apresentam eficiência na administraçáo de seus recursos destinados à escola. Dessa forma, convém indagar se o investimento de tais recursos na infraestrutura das escolas da RMC repercute no desempenho dos estudantes nas notas de proficiência do SPAECE.

Para o exame de tal questáo, o objetivo deste trabalho é mensurar o efeito da infraestrutura das escolas estaduais da RMC nas notas de proficiência do SPAECE no 
período de 2008 a 2015. Especificamente, recorre-se a modelos com dados em painel buscando estimar regressôes para explicar o efeito exercido pela infraestrutura física das escolas nas notas de língua portuguesa e matemática obtidas no SPAECE pelas escolas da RMC.

Este tipo de estudo enriquece o debate acerca dos efeitos da infraestrutura no desempenho discente, particularmente para a RMC. Nessa linha, apesar de haver dissonância em relação aos elementos que produzem efeitos positivos no desempenho dos alunos, Vasconcelos et al. (2020) são enfáticos ao afirmarem que o desempenho do aluno não depende apenas do seu esforço e que cabe ao poder público fornecer meios para que as escolas possuam insumos que possibilitem desenvolver atividades de qualidade permitindo o acesso ao ambiente favorável ao aprendizado e mitigando as desigualdades escolares. A relevância do papel exercido pelos governos na construção e na melhoria das instalaçóes físicas das unidades escolares com o intuito de promover ambientes de aprendizagem seguros e inclusivos também é defendida pela Organização das Naçôes Unidas para a Educação, a Ciência e a Cultura (UNESCO, 2019). Tais colocaçôes ratificam a importância de estudos dessa natureza como proposto neste trabalho.

Além desta introdução, este artigo está estruturado em mais quatro seções. A segunda discute inferências da literatura internacional e nacional acerca do efeito da infraestrutura escolar no desempenho discente; a terceira se dedica aos procedimentos metodológicos da pesquisa; enquanto as duas últimas, respectivamente, apresentam a análise dos resultados e as consideraçōes finais.

\section{INFRAESTRUTURA FÍSICA ESCOLAR E DESEMPENHO DISCENTE}

$\mathrm{Na}$ literatura econômica internacional e nacional, constatam-se evidências robustas de que a escolaridade é uma variável de relevada influência no progresso econômico, seja dos indivíduos ou das nações (FELÍCIO; FERNANDES, 2005). Por essa ótica, atribui-se a escola um papel fundamental na construção da sociedade, sendo discutida pela própria sociedade civil, governo e estudiosos. Neste particular, Vasconcelos et al. (2020) destacam que a infraestrutura das escolas, investimento e desempenho do discente são elementos indissociáveis. Tal acepção motiva debates e pesquisas acadêmicas acerca do impacto da infraestrutura escolar no rendimento dos alunos.

Nesse rol, Heyneman e Loxley (1983), explorando diversas influências no desempenho dos alunos da África, Ásia, América Latina e Oriente Médio, concluíram que, em países de baixa renda, também denominados de países em desenvolvimento, o efeito da escola e dos professores é comparativamente maior em relação aos países desenvolvidos. Desta forma, sinalizaram ainda, que a qualidade das escolas e os professores são influências predominantes na aprendizagem dos alunos. Por outra via, a pesquisa de Lee, Franco e Albernaz (2004), realizada com dados do Programa Internacional de Avaliação de Estudantes (PISA) em nível mundial, constata correlação entre infraestrutura e desempenho dos alunos, especialmente no Brasil, Portugal e Estados Unidos.

No cerne desta questão, a infraestrutura escolar, que engloba instalaçôes, equipamentos pedagógicos e serviços se constitui uma variável que possui impacto sobre o rendimento 
escolar, contudo, conforme Garcia (2014), isso não acontece em países desenvolvidos, sendo traço predominante daqueles em desenvolvimento. Essa argumentação é endossada por Gomes e Regis (2012), ao relataram que, em países em desenvolvimento, como é o caso do Brasil, os insumos escolares são significativos tendo em vista a grande viabilidade destes recursos pelas escolas no território nacional.

Felício e Fernandes (2005) destacam que uma hipótese levantada com razoável frequência nos estudos admite que, observada pela teoria da produção, a função de produção das escolas é côncava em relação aos seus insumos. Deste modo, os alunos de escolas pobres se beneficiam dos incrementos e de mais insumos, todavia, a partir de certo nível de recursos, os incrementos poderiam ser poucos significantes. Essa constatação é mais significante quando as análises consideram países em que as escolas possuem maior dotação de recursos e países com baixo grau de insumos em suas unidades educacionais.

Franco et al. (2007), por seu turno, considerando uma amostra de dados da proficiência em matemática de alunos do quarto ano do ensino fundamental no Sistema de Avaliação da Educação Básica (SAEB), de 2001, enfatizam que a escola faz diferença no desempenho discente. Para esses autores, o clima acadêmico, que fora captado pelo hábito de atribuir tarefas de casa para alunos e fazer correção em sala de aula; a organização de espaço para livros no interior da sala de aula e a manutenção de um clima disciplinar; a liderança do diretor que permite a colaboraçáo entre os docentes; e a existência de recursos escolares, como a disponibilidade e a conservação de equipamentos, a existência de pessoal e recursos propriamente financeiros são fatores que influenciam o desempenho dos alunos.

Vasconcelos et al. (2020) salientaram que, apesar da infraestrutura das escolas brasileiras terem melhorado entre 2007 e 2017, ainda há baixa implementação de itens que assegurem o funcionamento básico das unidades escolares. No bojo dessa realidade, chamam atenção para as desigualdades entre as escolas do país, que afetam os alunos desfavorecidos. $\mathrm{Na}$ contramão, observaram significante relação entre investimento público em educação e infraestrutura escolar dos municípios, sinalizando a importância dessas variáveis para o desempenho acadêmico. Ademais, tais autores fizeram a ressalva que a alocação dos recursos destinados à infraestrutura das escolas deve ser eficiente para que os municípios exerçam uma boa atuação, refletindo no desempenho dos discentes.

Evidências, neste sentido, são constatadas também para as unidades federativas brasileiras e as regiôes metropolitanas. Gomes e Regis (2012), com microdados do Censo Escolar 2009 e da Prova Brasil 2009, mostram uma relação inversa entre o índice de dependência (composto pelas variáveis concernentes à sala de professores, laboratórios de informática e de ciências, quadra de esportes e biblioteca e/ou sala de leitura) e as notas de proficiência em matemática para as escolas públicas da Região Metropolitana do estado do Rio de Janeiro. Por outro lado, as análises apontaram efeitos positivos decorrentes da conservação dos equipamentos escolares, sinalizando que os municípios que adotam políticas com vista a ampliação da infraestrutura escolar não necessariamente alcançam êxito quando comparadas as políticas de conservação e uso da infraestrutura dos ambientes educacionais.

Silva e Nascimento (2019), por sua vez, buscaram analisar a relação entre o desempenho dos discentes, o processo de urbanização e a infraestrutura escolar. Para tal, 
consideraram como objeto de estudo a escola pública CED 01 em Brasília e utilizaram dados do Censo Escolar 2017. Segundo esses autores, quanto melhor a infraestrutura e o ambiente escolar, melhor será o desempenho do estudante, porém a presença única desses recursos náo pode ser considerada como suficiente para promover a aprendizagem do aluno.

Considerando 1052 escolas estaduais e municipais do Rio Grande do Norte, Rocha, Teixeira e Melo (2015) constataram efeito da existência de biblioteca, elemento da infraestrutura física, nas notas de língua portuguesa no desempenho escolar dos alunos do quinto e nono ano. Para o desempenho em matemática, a presença de biblioteca na escola acarreta efeito positivo e significativo apenas para os discentes do nono ano. Particularmente, para o Ceará, em uma análise sobre os determinantes da proficiência no SPAECE com alunos do terceiro ano do ensino médio de 441 escolas, Monteiro, Castelar e Sousa (2017) encontraram efeito positivo e significante da infraestrutura como determinante da nota de língua portuguesa do SPAECE. Quanto às notas de matemática no SPAECE, a infraestrutura não se mostrou significante e, além disso, observaram crescimento nas notas de língua portuguesa em relação às de matemática, argumentando que as políticas públicas foram mais eficazes nos exames de português.

Desta forma, diante dessa literatura discutida, ratifica-se que o presente estudo contribui para as discussóes acerca dos efeitos dos insumos escolares (nesse caso, a infraestrutura física) no desempenho dos discentes em língua portuguesa e matemática, especificamente no SPAECE, na Regiáo Metropolitana do Cariri, interior do estado do Ceará.

\section{METODOLOGIA}

\section{1 Área de estudo, variáveis e fonte dos dados}

A Regiăo Metropolitana do Cariri (RMC) é uma das três regióes metropolitanas do estado do Ceará e foi criada pela lei complementar ${ }^{\circ} 78$, de 28 de junho de 2009 (CEARÁ, 2009). Segundo Morais e Macedo (2014), o principal aspecto considerado no surgimento da RMC, conforme a lei que a instituiu, foi a necessidade de reduçáo das desigualdades regionais no Ceará mediante investimentos estruturais e financeiros para promoção do desenvolvimento dos municípios localizados no interior do Estado. Formada como unidade geoeconômica, social e cultural, é composta por nove municípios, a saber: Barbalha, Caririaçu, Crato, Farias Brito, Jardim, Juazeiro do Norte, Missão Velha, Nova Olinda e Santana do Cariri, conforme ilustrada na Figura 1.

Em 2018, o Instituto de Pesquisa e Estratégica Econômica do Ceará (IPECE, 2018) estimou a população da RMC em 605.518 habitantes, um aumento de 5,38\% em relação a 2012. Esse contingente se distribui pelo território com densidade demográfica de 110,90 habitantes por quilômetros quadrados, perfazendo a segunda maior densidade entre as regióes metropolitanas do Ceará, devido ao fato de abranger municípios com grande concentraçáo populacional, como os que compóem a conurbação do triângulo CRAJUBAR (Crato, Juazeiro do Norte e Barbalha). A esse respeito, Morais e Macedo (2014) ressaltam que essas três cidades constituem as principais da RMC e concentram a maior parte da população e 
dos melhores indicadores socioeconômicos regionais, visto que agregam economias de polo industrial, comercial e de serviços.

Figura 1: Localização geográfica dos municípios que compõem a RMC

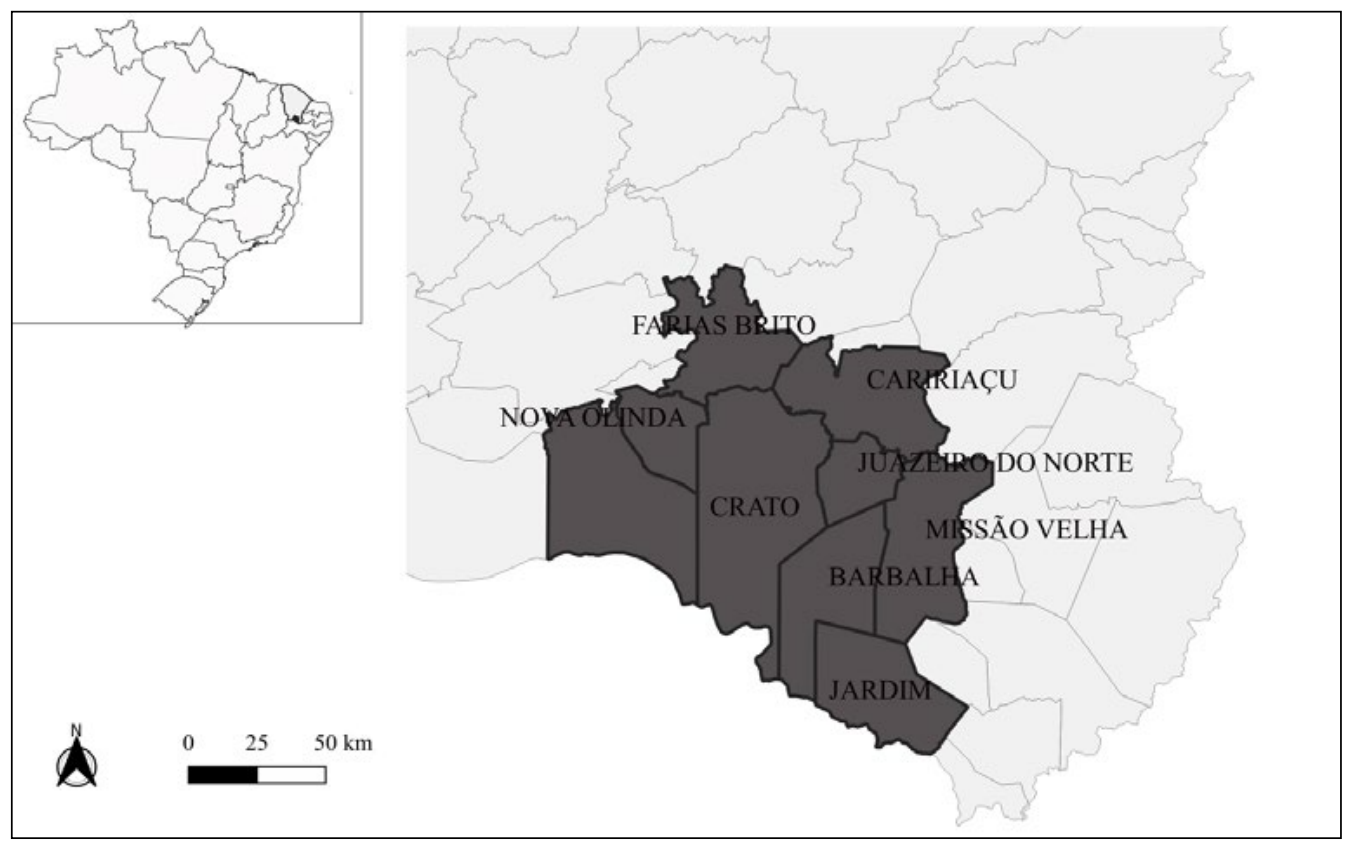

Fonte: Elaborada pelos autores.

Segundo dados do Anuário Estatístico do Ceará (IPECE, 2017), em 2015, havia 40 escolas estaduais na RMC. Desse quantitativo, para a base de dados deste estudo, foram consideradas 33 escolas, assim distribuídas: Barbalha (3) Caririaçu (2); Crato (10); Farias Brito (2); Jardim (1); Juazeiro do Norte (11); Missão Velha (2); Nova Olinda (1); e Santana do Cariri (1). O critério de escolha consistiu em selecionar as unidades escolares que apresentaram notas de proficiências em língua portuguesa e matemática do primeiro ano do ensino médio em todos os anos do período considerado.

As informaçôes da proficiência no SPAECE e de infraestrutura destas escolas foram retiradas da base de dados Estatística da Educação no Ceará da Secretaria de Educação do Ceará (SEDUC). O Quadro 1 apresenta as variáveis explicativas, que caracterizam a infraestrutura das escolas, adotadas neste estudo. 
Quadro 1: Descrição das variáveis utilizadas

\begin{tabular}{|c|c|}
\hline Nome & Descriçáo \\
\hline \multicolumn{2}{|r|}{ Variável dependente } \\
\hline profic_mat & $\begin{array}{l}\text { Proficiência média em matemática no SPAECE no primeiro ano do } \\
\text { ensino médio }\end{array}$ \\
\hline profic_por & $\begin{array}{l}\text { Proficiência média em língua portuguesa no SPAECE no primeiro } \\
\text { ano do ensino médio }\end{array}$ \\
\hline \multicolumn{2}{|r|}{ Variáveis independentes } \\
\hline Audit & 1 , se a escola possui auditório, e 0 , caso contrário \\
\hline Refeit & 1 , se a escola possui refeitório, e 0 , caso contrário \\
\hline Bibli & 1 , se a escola possui biblioteca, e 0 , caso contrário \\
\hline s_leit & 1 , se a escola possui sala de leitura, e 0 , caso contrário \\
\hline s_atend_esp & 1 , se a escola possui sala de atendimento especial, e, 0 , caso contrário \\
\hline lab_infor & 1 , se a escola possui laboratório de informática, e, 0 , caso contrário \\
\hline lab_cienc & 1, se a escola possui laboratório de ciência, e, 0 , caso contrário \\
\hline quad_espor & 1 , se a escola possui quadra de esportes, e, 0 , caso contrário \\
\hline area_verd & 1 , se a escola possui área verde, e, 0 , caso contrário \\
\hline poss_comp & 1 , se a escola possui computador, e, 0 , caso contrário \\
\hline conex_inter & 1 , se a escola possui conexão com a internet, e, 0 , caso contrário \\
\hline Diret & 1 , se a escola possui diretoria, e, 0 , caso contrário \\
\hline s_prof & 1 , se a escola possui sala de professores, e, 0 , caso contrário \\
\hline int_band_larg & 1 , se a escola possui internet banda larga, e, 0 , caso contrário \\
\hline Regul & 1 , se a escola é regulamentada, e, 0 , caso contrário \\
\hline
\end{tabular}

Fonte: Elaborado pelos autores.

O recorte dos dados compreende o interstício temporal de 2008 a 2015, totalizando 264 observaçóes. Conforme salientado, a escolha deste período temporal levou em consideração a existência de dados para as notas de proficiência em língua portuguesa e matemática e da infraestrutura das escolas de forma a abranger o maior período em que há disponibilidade de dados para maior quantidade de estabelecimentos educacionais da $\mathrm{RMC}$, de forma a majorar a amostra.

\subsection{Métodos analíticos}

Para captar o efeito da infraestrutura das escolas estaduais da RMC nos resultados do SPAECE, aplicou-se um modelo de regressão de dados em painel. O caso geral de um modelo com dados em painel é apresentado na equação (1). Esta modelagem é caracterizada por variáveis de séries temporais que provêm das mesmas unidades amostrais (cross-section), ou seja, pela combinação de séries temporais e dados de corte transversal. Tal estrutura possibilita captar a heterogeneidade entre tais unidades da amostra e, além disso, majora a eficiência das estimativas (REINALDO,2017). 
Neste estudo, a heterogeneidade, constante no tempo e distinta entre cada crosssection, pode ser apontada como os aspectos cognitivos das escolas da RMC (MONTEIRO; CASTELAR; SOUSA, 2017). Assim, para estimar os coeficientes da regressão, pode-se eliminar ou controlar tal heterogeneidade. Com isso, geram-se diversos modelos, como os de dados agrupados (pooled), efeitos fixos e efeitos aleatórios.

$$
y_{i t}=\beta_{0}+\beta_{i} x_{i t}+\varepsilon_{i t}+c_{i}
$$

$\mathrm{Na}$ equação (1), a variável dependente $y_{i t}$ representa a variável em que o modelo busca explicar; $\mathrm{x}_{\mathrm{it}}$ diz respeito ao conjunto de variáveis explicativas, ambas na dimensão $i$ e no tempo $t$, caracterizando a estrutura de painel; o termo $\varepsilon_{i t}$ representa um componente idiossincrático e $c_{i} c_{i}$ é um efeito individual constante no tempo, conforme Monteiro, Castelar e Sousa (2017) e Reinaldo (2017). Portanto, se $c_{i} c_{i}$ for correlacionado com $x_{i t}$, utiliza-se o modelo com efeitos fixos, e se $c_{i}$ não for correlacionado com $x_{i t}$, opta-se pelo modelo com efeitos aleatórios (REINALDO, 2017).

Para escolher a modelagem adequada, realizaram-se diversos testes estatísticos, como o teste $\mathrm{F}$ de Chow, em que se for significante, utiliza-se o modelo de efeitos fixos, caso contrário, a regressão pooled é mais adequada; o teste do Multiplicador de Lagrange de Breusch e Pagan, caso seja significativo, a literatura preconiza o modelo de efeitos aleatórios e, ao contrário, o modelo pooled (PRATES; SERRA, 2009); e o teste de Hausman, quando significativo, mostra que o modelo de efeitos fixos é preferível ao modelo de efeitos aleatórios, e quando não significativo, recomenda-se o modelo de efeitos aleatórios(GUJARATI; PORTER, 2008).

Considerando a modelagem apresentada na equaçáo (1), neste estudo, foram estimados dois modelos semilogarítmicos, para a proficiência no SPAECE em língua portuguesa e matemática, conforme a equação (2).

$$
\ln \text { profic }_{\mathrm{it}}=\beta_{0}+\beta_{\mathrm{i}} \mathrm{x}_{\mathrm{it}}+\varepsilon_{\mathrm{it}}+\mathrm{c}_{\mathrm{i}}
$$

Em que ln profic $_{\text {it }}$ é o logaritmo natural da proficiência no SPAECE (em língua portuguesa e matemática, para cada modelo) do primeiro ano do ensino médio da escola $i$ ano $t ; x_{i t}$ refere-se ao vetor de variáveis independentes e se reporta ao conjunto de dummies referentes à infraestrutura das escolas, conforme o Quadro 1; os subescritos $i$ e $t$ indicam, respectivamente, as escolas incluídas neste estudo $(i=1,2, \ldots, 33)$ e os períodos em anos $(t=1,2, \ldots 8)$.

As variaçôes nos parâmetros nos modelos são interpretadas conforme a taxa de crescimento composta ( $\mathrm{r}$ ) da cada parâmetro obtida pela expressão (3), seguindo o entendimento de Gujarati e Porter (2008).

$$
\mathrm{r}=\left[\left(\operatorname{antilog} \beta_{\mathrm{i}}-1\right) * 100\right]
$$


Sendo assim, estimou-se a regressão (2) considerando os modelos pooled, efeitos fixos e efeitos aleatórios, e aplicaram-se os testes para verificar o modelo mais adequado e discutem-se os resultados obtidos por este. Além disso, foram aplicados testes para verificar a presença de heterocedasticidade, correlação serial entre as variáveis explicativas e se os resíduos do modelo se comportam conforme a distribuição normal. Tais procedimentos foram realizados no software $\mathrm{R}$ Studio versão 4.0.3.

\section{RESULTADOS E ANÁLISES}

Seguindo os procedimentos metodológicos, a Tabela 1 apresenta os testes de ajuste e violação das hipóteses do modelo que busca explicar o efeito da infraestrutura nas notas de proficiência em língua portuguesa e matemática do SPAECE na RMC. À luz desta tabela, tanto para proficiência em língua portuguesa quanto em matemática, constata-se que o modelo com efeitos fixos é preferível à regressão pooled, assim como, o modelo com efeitos aleatórios deve ser adotado em relação à regressão pooled, a $1 \%$, conforme os testes $\mathrm{F}$ de Chow e do Multiplicador de Lagrange de Breusch e Pagan, respectivamente. Pelo teste de Hausman, também a 1\% de significância, indica-se que o modelo com efeitos fixos é o mais adequado para os dois conjuntos de variáveis. Ressalta-se a consonância com a literatura, uma vez que esta modelagem foi utilizada por Monteiro, Castelar e Sousa (2017) para investigar os determinantes das notas de proficiência do terceiro ano do ensino médio no SPAECE no estado do Ceará de 2008 a 2014.

Tabela 1: Testes para ajuste do modelo e violação das hipóteses do modelo de regressão linear

\begin{tabular}{l|l|c|c}
\hline \multirow{2}{*}{ Teste } & \multicolumn{1}{c|}{ Hipóteses } & \multicolumn{2}{c}{ Estatística } \\
\cline { 3 - 4 } F de Chow & $\begin{array}{c}\text { Proficiência em } \\
\text { língua portuguesa }\end{array}$ & $\begin{array}{c}\text { Proficiência em } \\
\text { matemática }\end{array}$ \\
\hline LM de Breusch-Pagan & $\begin{array}{l}\mathrm{H}_{0}: \text { Pooled } \\
\mathrm{H}_{1}: \text { Efeito fixo } \\
\mathrm{H}_{1}: \text { Efeoled }\end{array}$ & $1,9518^{* * *}$ & $6,376^{* * *}$ \\
\hline Hausman & $\begin{array}{l}\mathrm{H}_{0}: \text { Efeito aleatório } \\
\mathrm{H}_{1}: \text { Efeito fixo }\end{array}$ & $301,86^{* * *}$ & $134,5^{* * *}$ \\
\hline Breusch-Pagan & $\begin{array}{l}\mathrm{H}_{0}: \text { Ausência de } \\
\text { heterocedasticidade } \\
\mathrm{H}_{1}: \text { Presença de } \\
\text { heterocedasticidade }\end{array}$ & $369,81^{* * *}$ & $67,093^{* * *}$ \\
\hline Wooldridge & $\begin{array}{l}\mathrm{H}_{0}: \text { Ausência de correlação serial } \\
\mathrm{H}_{1}: \text { Presença de correlação serial }\end{array}$ & $15,297^{* * *}$ & $110,7^{* * *}$ \\
\hline Shapiro-Wilk & $\begin{array}{l}\mathrm{H}_{0}: \text { Resíduos seguem a normal } \\
\mathrm{H}_{1}: \text { Resíduos não seguem a normal }\end{array}$ & 0,99272 & $0,74042^{* * *}$ \\
\hline
\end{tabular}

Nota: ${ }^{*} \mathrm{p}<0,1 ;{ }^{* *} \mathrm{p}<0,05 ;{ }^{* * *} \mathrm{p}<0,01$

Fonte: elaborada pelos autores para os dados de 2008 a 2014. 
Quanto aos testes de violação das hipóteses do modelo, apresentados na parte inferior da Tabela 1, o teste de Breusch-Pagan, aplicada para verificar a presença de heterocedasticidade, rejeita a hipótese que a variância seja constante, isto é, a variância dos resíduos dos dois modelos é heterocedástica. Na mesma linha, o teste de Wooldridge, considerando a estatística de $1 \%$, mostra a presença de correlação serial para variáveis de ambos os modelos. Por outro lado, o teste Shapiro-Wilk não rejeita a hipótese nula que os resíduos do modelo de regressão com variável dependente língua portuguesa seguem uma distribuição normal, ao passo que essa hipótese é rejeitada para o termo de perturbação estocástica do modelo de proficiência em matemática.

Dentre tais hipóteses, diante à validação da presença de heterocedasticidade, é necessária a correção por erro-padrão robusto com vistas a não subestimar os testes de significância (COSTA; CALDEIRA; CAIXETA-FILHO, 2020). Para tal, aplicou-se a matriz de erro-padrão de White. Feito isso, obtêm-se os modelos estimados com efeitos fixos que apontam os efeitos da infraestrutura das escolas da RMC nas notas de proficiência em língua portuguesa e matemática do primeiro ano do ensino médio no SPAECE expostos na Tabela 2.

Dessa forma, os resultados obtidos pelo modelo com efeitos fixos revelam que as variáveis consideradas da infraestrutura das escolas estaduais explicam, respectivamente, $34 \%$ e 4,9\% das variações no logaritmo das notas de proficiência em português e matemática do primeiro ano do ensino médio no SPAECE e os dois modelos são estatisticamente significantes, já que o p-valor do teste $\mathrm{F}$ foi menor que o nível de significância de $1 \%$.Considerando o baixo grau de ajuste dos modelos, reconhecem-se outros fatores que explicam o desempenho dos alunos. Conforme Soares e Andrade (2006), os determinantes do desempenho cognitivo dos alunos pertencem a três grandes categorias, a saber: a estrutura da escola, a família e as características do próprio aluno. Reitera-se que este estudo centraliza unicamente o efeito da infraestrutura, que, por sua vez, pertence à esfera da influência exercida pela escola.

Tabela 2: Estimaçóes com efeitos fixos para a influência da infraestrutura das escolas da RMC nas notas de proficiência em língua portuguesa e matemática do primeiro ano do ensino médio no SPAECE, 2008 a 2015

\begin{tabular}{lcc}
\hline \multirow{2}{*}{ Variáveis explicativas } & \multicolumn{2}{c}{ Variáveis dependentes } \\
\cline { 2 - 3 } & $\begin{array}{c}\text { Logaritmo da proficiência em } \\
\text { língua portuguesa }\end{array}$ & $\begin{array}{c}\text { Logaritmo da proficiência em } \\
\text { matemática }\end{array}$ \\
\hline \multirow{2}{*}{ audit } & $0,022^{* *}$ & 0,090 \\
& $(0,009)$ & $(0,104)$ \\
\hline \multirow{2}{*}{ refeit } & $0,024^{* * *}$ & $0,268^{*}$ \\
& $(0,008)$ & $(0,139)$ \\
\multirow{2}{*}{ bibli } & $-0,011$ & $-0,007$ \\
& $(0,009)$ & $(0,033)$ \\
\multirow{2}{*}{ s_leit } & $-0,014^{* *}$ & 0,045 \\
& $(0,005)$ & $(0,041)$ \\
\hline
\end{tabular}




\begin{tabular}{|c|c|c|}
\hline \multirow[b]{2}{*}{ Variáveis explicativas } & \multicolumn{2}{|c|}{ Variáveis dependentes } \\
\hline & $\begin{array}{c}\text { Logaritmo da proficiência em } \\
\text { língua portuguesa }\end{array}$ & $\begin{array}{c}\text { Logaritmo da proficiência em } \\
\text { matemática }\end{array}$ \\
\hline \multirow{2}{*}{ s_atend_esp } & $-0,014^{*}$ & 0,090 \\
\hline & $(0,008)$ & $(0,072)$ \\
\hline \multirow{2}{*}{ lab_infor } & 0,027 & 0,347 \\
\hline & $(0,022)$ & $(0,270)$ \\
\hline \multirow{2}{*}{ lab_cienc } & $0,018^{* *}$ & 0,012 \\
\hline & $(0,008)$ & $(0,033)$ \\
\hline \multirow{2}{*}{ quad_espor } & 0,003 & $-0,060$ \\
\hline & $(0,007)$ & $(0,075)$ \\
\hline \multirow{2}{*}{ area_verd } & $0.022^{* *}$ & $-0,074$ \\
\hline & $(0,009)$ & $(0,061)$ \\
\hline \multirow{2}{*}{ poss_comp } & $-0,054^{* *}$ & $-0,180$ \\
\hline & $(0,025)$ & $(0,148)$ \\
\hline \multirow{2}{*}{ conex_inter } & $-0,015$ & $-0,046$ \\
\hline & $(0,023)$ & $(0,047)$ \\
\hline \multirow{2}{*}{ diret } & $0,032^{* *}$ & $0,145^{* *}$ \\
\hline & $(0,016)$ & $(0,062)$ \\
\hline \multirow{2}{*}{ s_prof } & $-0,012$ & 0,061 \\
\hline & $(0,015)$ & $(0,047)$ \\
\hline \multirow{2}{*}{ int_band_larg } & $0,050^{* * *}$ & $0,064^{* *}$ \\
\hline & $(0,006)$ & $(0,027)$ \\
\hline \multirow{2}{*}{ regul } & 0,0003 & $-0,189^{*}$ \\
\hline & $(0,006)$ & $(0,107)$ \\
\hline $\mathrm{N}$ & 264 & 264 \\
\hline $\mathrm{R}^{2}$ & 0,458 & 0,219 \\
\hline Adjusted $\mathrm{R}^{2}$ & 0,340 & 0,049 \\
\hline F Statistic $(\mathrm{df}=15 ; 216)$ & $12,154^{* * *}$ & $4,042^{* * *}$ \\
\hline
\end{tabular}

Nota: ${ }^{*} \mathrm{p}<0,1 ;{ }^{* *} \mathrm{p}<0,05 ;{ }^{* * *} \mathrm{p}<0,01$

Fonte: elaborada pelos autores para os dados de 2008 a 2014.

Por meio do modelo estimado para as notas de proficiência em língua portuguesa, infere-se que a existência de refeitório (refeit) e internet banda larga (int_band_larg) exercem influência positiva e estatisticamente significante a 1\%; já auditório (audit), laboratório de ciências (lab_cienc), área verde (area_verd) e diretoria (diret) afetam positivamente as notas com significância de 5\%; ao passo que sala de leitura (s_leit) e possuir computador (poss_ comp), com a mesma estatística, ocasionam efeitos negativos; adicionada a estas, significante a $10 \%$, a presença sala de atendimento especial (s_atend_esp) reduz o desempenho em língua portuguesa no SPAECE.

Tudo mais constante, o fato da escola da RMC possuir refeitório em suas dependências aumenta a nota de proficiência em língua portuguesa em 2,42\% 
[(antilog $0,022-1) * 100]$; o acesso à internet via banda larga aumenta a nota em 5,12\%; a presença de auditório incrementa a nota em 2,22\%; enquanto laboratório de ciências aumenta a nota em 1,81\%; a área verde na escola eleva a nota em 2,22\%; enquanto diretoria incrementa a nota em 3,25\%. Soares e Werle (2021) defendem que os diretores das escolas influenciam positivamente o aprendizado dos discentes, uma vez que se envolvem diretamente com o pedagógico, fazendo um monitoramento individualizado do desempenho do aluno, inclusive com domínios teóricos e práticos das estratégias de leitura. Por outro lado, reduzem as notas de proficiência em língua portuguesa no SPAECE na RMC: a existência de sala de leitura $(1,39 \%)$; computador $(5,25 \%)$ e sala de atendimento especial (1,39\%).

Em relação às evidências que insumos da infraestrutura escolares que afetam as notas de língua portuguesa, Rocha, Teixeira e Melo (2015) encontraram que a presença de uma biblioteca por escola aumenta em aproximadamente 2 pontos percentuais o desempenho dos estudantes do quinto ano e 3 pontos percentuais para os discentes do nono ano de escolas municipais e estaduais do Rio Grande do Norte. No presente estudo, as características inerentes à variável biblioteca sáo captadas pela variável sala de leitura. No que alinha à literatura estadual, particularmente em nível cearense, reitera-se que a infraestrutura escolar exerce efeito positivo no desempenho no SPAECE em português (MONTEIRO; CASTELAR; SOUSA, 2017). A influência desse efeito pode ser resultado de políticas direcionadas a mitigar à evasão escolar e repetência. Tais políticas ocorrem mediante campanhas para melhorar a infraestrutura das escolas, qualificação de docentes e gratificação aos gestores (SHIRASU; ALBUQUERQUE; ARRAES, 2014).

Com relação ao efeito da infraestrutura das escolas da RMC nas notas de proficiência do SPAECE em matemática, a Tabela 2 revela que a presença de diretoria (diret) e internet banda larga (int_band_larg) influenciam a nota de proficiência de modo positivo estatisticamente significante a 5\%; enquanto o refeitório (refeit) e a escola ser regulamentada (regul) afetam a nota de forma positiva e negativa, respectivamente, a $10 \%$. Nesse sentido, tudo mais constante, há um acréscimo de $15,6 \%$ nas notas de proficiência em matemática quando a escola possui diretoria; 6,6\% 30,73\%, respectivamente, se o acesso à internet for banda larga e existir refeitório na unidade escolar; ao passo que se reduz $17,22 \%$ quando a escola é regulamentada.

Tais resultados indicam que a infraestrutura escolar de forma majoritária não repercute efeitos sobre as notas de proficiência em matemática no SPAECE, estando de acordo a literatura para nível estadual cearense (MONTEIRO; CASTELAR; SOUSA, 2017). Ressalta-se que estas inferências são corroboradas por pesquisas realizadas paras outras regiōes do Brasil. Nesse sentido, Gomes e Regis (2012) construíram um índice de dependência (incluindo variáveis estruturais como: sala de professores, laboratórios de informática e de ciências, quadra de esportes e biblioteca e/ou sala de leitura) e verificaram impacto negativo deste indicador no desempenho médio das escolas da Regiáo Metropolitana do Rio de Janeiro em matemática na Prova Brasil. Além disso, para este caso dos resultados em matemática, podem-se observar as evidências encontradas por algumas 
pesquisas (GOMES, 2005) que existência de recursos diretamente relacionados ao aluno têm mais efeito que as instalaçóes das escolas.

Por outro lado, considerando os resultados obtidos para as estimaçóes de ambos os modelos, constata-se dissonância com Franco et al. (2007). Os autores supracitados sustentam que os insumos da infraestrutura das escolas apresentam maior efeito no desempenho em matemática, justificando que o conhecimento da língua nativa, nesse caso, a língua portuguesa, desenvolve-se em diversos ambientes frequentados pelos discentes e não necessariamente na escola. Essa percepção é endossada por Felício e Fernandes (2005), ao salientarem que os insumos escolares possuem pouca influência no desempenho escolar quando comparado ao background familiar.

\section{CONSIDERAÇÓES FINAIS}

Os resultados estimados confirmam efeito da infraestrutura das escolas estaduais da RMC no desempenho no SPAECE. Especificamente, a presença de refeitório, internet banda larga, auditório, laboratório de ciências, área verde e diretoria influenciam positivamente as notas de proficiência em português, ao passo que existência de diretoria, internet banda larga e refeitório impactam de forma positiva o desempenho em matemática do primeiro ano do ensino médio no SPAECE.

Dessa forma, respondendo ao problema de pesquisa do presente estudo, verificou-se que o investimento em determinados segmentos da infraestrutura das escolas estaduais da RMC repercute efeito positivo no desempenho de tais escolas no SPAECE, especialmente em língua portuguesa. Esta última evidência empírica apresenta dissonância com a literatura nacional, visto que estudos preconizam que o efeito escolar é mais influente no desempenho em matemática, já que o aprendizado da língua portuguesa pode ocorrer com maior intensidade em ambientes externos à escola.

Estes resultados sinalizam que políticas de infraestrutura escolar destinadas ao aumento das notas de proficiência no SPAECE tiveram melhores efeitos sobre os exames de língua portuguesa. Por essa via, pode-se ainda considerar a necessidade de políticas adequadas aos aspectos cognitivos dos alunos, bem como meios que promovam equidade entre os insumos escolares, uma vez que a infraestrutura adequada, ao lado da família e sociedade, cumpre seu papel primordial na formação do discente, de forma a reduzir as desigualdades econômicas e sociais.

É importante frisar que, no contexto do papel da escola para o desenvolvimento social e econômico, a infraestrutura e os insumos em geral adquirem expressiva influência na aprendizagem do aluno. No caso das escolas públicas, especialmente em países em desenvolvimento, a qualidade destes insumos encontra-se muitas vezes distantes do ideal. Desta forma, compete aos formuladores de políticas, bem como a sociedade contribuir para que a escola se torne um instrumento eficaz na formação discente promovendo equidade e alavancando o crescimento do indivíduo e repercutindo no desenvolvimento econômico das regióes metropolitanas, bem como do país.

Por fim, sugere-se a realização de estudos posteriores que busquem identificar os motivos pelos quais a infraestrutura das escolas apresenta baixos efeitos no desempenho 
em matemática, bem como propor estratégias que possibilitem utilizar os recursos e as instalaçóes das escolas de forma a maximizar o desempenho dos estudantes da RMC. Além disso, recomenda-se que o debate e as análises empíricas sejam ampliados considerando todos os municípios do estado do Ceará, assim como outras variáveis que explicam o desempenho discente, como o efeito do aluno, da família e os fatores associados às peculiaridades econômicas e sociais dos municípios que situam os estabelecimentos escolares.

\section{REFERÊNCIAS}

CEARÁ. Lei complementar n ${ }^{\circ} 78$, de 28 de junho de 2009. Dispóe sobre a criação da Regiáo Metropolitana do Cariri, cria o Conselho de Desenvolvimento e Integração e o Fundo De Desenvolvimento e Integração da Região Metropolitana do Cariri - FDMC, altera a composição de microrregióes do Estado do Ceará e dá outras providências. Diário Oficial do Estado: série 3, Fortaleza, ano 1, n. 124, p. 1-2, 03 jul. 2009.

COSTA, E. L.; CALDEIRA, P. M. A.; CAIXETA-FILHO, J. V. Importância das chuvas no frete de açúcar para exportação no estado de São Paulo. Estudo \& Debate, Lajeado, v. 27, n. 3, p. 68-89, 2020.

FELÍCIO, F.; FERNANDES, R. O efeito da qualidade da escola sobre o desempenho escolar: uma avaliaçáo do ensino fundamental no estado de São Paulo. In: Encontro Nacional de Economia, 33., 2005. Anais [...]. Rio Grande do Norte: ANPEC, 2005.

FRANCO, C.; ORTIGÃO, I.; ALBERNAZ, A.; BONAMINO, A.; AGUIAR, G.; ALVES, F.; SÁTYRO, N. Qualidade e equidade em educação: reconsiderando o significado de "fatores intra-escolares". Ensaio: Avaliação de Políticas Públicas Educacionais, Rio de Janeiro, v.15, n.55, p. 277-298, abr./jun. 2007.

GARCIA, P. S. Um estudo de caso analisando a infraestrutura das escolas de ensino fundamental. Cadernos de Pesquisa: Pensamento Educacional, Curitiba, v. 9, n. 23, p.137-159 set./dez. 2014.

GOMES, A. C. A escola de qualidade para todos: abrindo as camadas da cebola. Ensaio: Avaliação de Políticas Públicas em Educação, Rio de Janeiro, v. 13, n. 48, p. 281-306, 2005.

GOMES, A.; REGIS, A. Desempenho e infraestrutura: mapeamento das escolas públicas da regiâo metropolitana do Rio de Janeiro. In: Congresso Ibero Americano de Política e Administração da Educação, 2., 2012. Anais [...]. Zaragoza, Espanha: ANPAE, 2012.

GUJARATI, D. N.; PORTER, D. C. Basic econometrics. 5th ed. New York: McGrawHill, 2008. 
HEYNEMAN, S. P.; LOXLEY, W. A. The effect of primary-school quality on academic achievement: across twenty-nine high-and low-income countries. American Journal of Sociology, v. 88, n. 6, p. 1162-1194, may. 1983.

INSTITUTO DE PESQUISA E ESTRATÉGIA ECONÔMICA DO CEARÁ - IPECE. Anuário Estatístico do Ceará 2017. 2017. Disponível em: http://www2.ipece.ce.gov.br/ publicacoes/anuario/anuario2017/qualidade/educacao/ensino_medio.htm. Acesso em: 01 fev. 2021.

INSTITUTO DE PESQUISA E ESTRATÉGIA ECONÔMICA DO CEARÁ - IPECE. Panorama socioeconômico das regióes metropolitanas cearenses. Fortaleza: IPECE, n. 1, dez. 2018.

\section{LEE, V.E.; FRANCO, C.; ALBERNAZ, A. Quality and equality in Brazilian}

secondary schools: a multilevel cross-national school effects study. Annual Meetingof the American Educational Research Association. San Diego, 2004.

MONTEIRO, V. B.; CASTELAR, P. U. C.; SOUSA, J. B. Determinantes do rendimento escolar nas escolas públicas de ensino médio do estado do Ceará: uma análise de painel sobre o SPAECE de 2008 a 2014. In: BARRETO, F. A. F. D.; FRANÇA, J. M.; ARAGÃO M.; SOUSA F. J. (Org.). Economia do Ceará em Debate 2017. Fortaleza: IPECE, 2017. p. 93-120.

MORAIS, J. M. L.; MACEDO, F. C. Regiōes Metropolitanas do Ceará: dispersão produtiva e concentração de serviços. Desenvolvimento Regional em debate, v. 4, n. 2, p. 178-203, 2014.

ORGANIZAÇÃO DAS NAÇÓES UNIDAS PARA A EDUCAÇÃO, A CIÊNCIA E A CULTURA - UNESCO. Qualidade da infraestrutura das escolas públicas do ensino fundamental no Brasil. Brasília, 2019.

PRATES, R. C.; SERRA, M. O impacto dos gastos do governo federal no desmatamento no estado do Pará. Nova Economia, Belo Horizonte, v. 19, n.1, p.95-116, 2009.

REINALDO, L. M. Estimaçáo clássica e baynesiana para dados em painel. 117 p. 2017. Dissertação (Mestrado em Estatística) - Universidade de Brasília, Brasília, DF, 2017.

ROCHA, F. A. F.; TEIXEIRA, J. C. M.; MELO, F. L. N. B. Análise dos fatores que influenciam o desempenho escolar dos alunos do ensino fundamental no estado do Rio Grande do Norte. Revista Interface, v. 12, n. 1, p. 89-108, jan./jul. 2015.

SHIRASU, M. R.; ALBUQUERQUE; ARRAES R. Determinantes da evasão e repetência escolar. In: BARRETO, F. A. F. D.; MENEZES, A. S. B.; ASSIS, D. N. C.; SOUSA, F. J. (Org.). Economia do Ceará em Debate 2014. Fortaleza: IPECE, 2014. p.195-241. 
SILVA, M. D. A.; NASCIMENTO, C. P. O processo de urbanização e sua influência no desenvolvimento da infraestrutura e desempenho dos alunos: uma análise a partir da escola CED 01 da cidade estrutural. Revista Projeçáo e Docência, v. 10, n. 1, p. 1-17, 2019.

SOARES, J. F.; ANDRADE, R. J. Nível socioeconômico, qualidade e equidade das escolas de Belo Horizonte. Ensaio: Avaliação e Políticas Públicas em Educação, Rio de Janeiro, v. 14, n. 50, p. 107-126, jan./mar. 2006.

SOARES, E. A.; WERLE, F. O. C. Sistema Permanente de Avaliação da Educação Básica do Ceará (SPAECE-ALFA): reconfigurando o contexto escolar? In: VIDAL, E. M.; COSTA, A. G. (Orgs.). Responsabilizaçáo educacional no Ceará: trajetórias e evidências. Brasília: ANPAE, 2021.

TROMPIERI NETO, N.; COSTA, L. O.; MEDEIROS, C. N.; KENNEDY F. Análise da eficiência das escolas estaduais cearenses. Texto para discussáo $\mathbf{n}^{\circ}$ 108. Fortaleza: IPECE, nov. 2014.

VASCONCELOS, J. C.; LIMA, P. V. P. L.; ROCHA, L. A.; KHAN, A. S. Infraestrutura escolar e investimentos públicos em Educação no Brasil: a importância para o desempenho educacional. Ensaio: Avaliação e Políticas Públicas em Educação, Rio de Janeiro, n. 2, p. 1-25, set. 2020. 